\title{
Pentazocine versus pentazocine with piroxicam for postoperative pain relief after cesarean section: an open label, comparative study
}

\author{
Banapura Ambika ${ }^{1 *}$, Mamatha K. R. ${ }^{1}$, Prabha P. ${ }^{2}$
}

\begin{abstract}
${ }^{1}$ Department of Pharmacology, ${ }^{2}$ Department of Anaesthesia, Bangalore Medical College and Research Institute, Bengaluru, Karnataka, India
\end{abstract}

Received: 21 March 2017 Accepted: 22 April 2017

\section{*Correspondence to: Dr. Banapura Ambika, Email: ambikabanapura101@ gmail.com}

Copyright: (C) the author(s), publisher and licensee Medip Academy. This is an openaccess article distributed under the terms of the Creative Commons Attribution NonCommercial License, which permits unrestricted noncommercial use, distribution, and reproduction in any medium, provided the original work is properly cited.

\begin{abstract}
Background: The concept of multimodal analgesia was introduced more than a decade ago as a technique to improve analgesia and reduce the incidence of opioid-related adverse events. The rationale for this strategy is the achievement of sufficient analgesia due to the additive or synergistic effects between different classes of analgesics. Objectives of the study was to compare the efficacy and safety of pentazocine and its combination with piroxicam in the management of post cesarean pain.

Methods: Cases were randomly assigned to 2 groups of 30 cases each. One group received pentazocine $30 \mathrm{mg}$ and another; pentazocine $30 \mathrm{mg}+$ piroxicam 20mg. Injections were given intramuscularly, postoperatively after skin closure. Diclofenac $75 \mathrm{mg}$ was the rescue analgesia. Primary outcome measure was control of pain, assessed by visual analogue scale (VAS). Secondary outcomes were sedation and time to rescue analgesia. Safety of the drugs was assessed by adverse drug reactions. Data was analysed by student's $t$ test, analysis of variance and post-hoc test.

Results: Multimodal group showed better analgesia compared to unimodal group $(\mathrm{p}<0001)$. Drowsiness was the main adverse effect in both treatment groups.

Conclusions: Multimodal analgesic combination of pentazocine and piroxicam showed superior analgesic effect with better pain control and longer duration of action compared to pentazocine alone.
\end{abstract}

Keywords: Pentazocine, Piroxicam, Post-cesarean pain

\section{INTRODUCTION}

The concept of multimodal analgesia was introduced more than a decade ago as a technique to improve analgesia and reduce the incidence of opioid-related adverse events. The rationale is the achievement of sufficient analgesia by additive effects between different classes of analgesics. This allows for a reduction in the doses of individual drugs and thus a lower incidence of adverse effects from any particular drug used for management of perioperative pain. A lower incidence of adverse effects and improved analgesia has been demonstrated with multimodal analgesia techniques, which may provide for shorter hospitalization times, improved recovery and function and possibly decreased healthcare costs. ${ }^{1,2}$ Currently, the American Society of
Anesthesiologists Task Force on Acute Pain Management advocates the use of multimodal analgesia. ${ }^{3}$

According to the WHO ladder, based on increasing pain severity the combination of nonsteroidal antiinflammatory drugs (NSAIDs) with opioids was considered as the second step in the treatment of pain. ${ }^{4}$

Pentazocine, a potent analgesic, with agonist-antagonist action at opioid receptors ${ }^{5}$ is widely used in low resources countries for postoperative analgesia.

NSAIDs and selective cyclooxygenase-2 inhibitors have beneficial effect on postoperative analgesia and their addition has been shown to potentiate opioid effect, decrease opioid consumption and are devoid of adverse 
effects of opioids. ${ }^{6,7}$ Piroxicam, NSAID, has long halflife, extensive protein binding which allows for its once a day dosing. ${ }^{8}$ Studies comparing the efficacy of pentazocine and its combination with piroxicam are limited. Although multimodal analgesic combinations are well accepted, finding the right combination remains the key challenge. ${ }^{9}$

We explored multimodal approach to pain relief after cesarean section using two different drugs with different routes of administration and mechanisms of action. We therefore compared the analgesic and side effect profile of intramuscular pentazocine alone or in combination with piroxicam.

\section{METHODS}

This study was a prospective, hospital-based, open label, parallel group, comparative study approved by the Institutional Ethics Committee of Bangalore Medical College and Research Institute.

Sixty patients of ASA (American Society of Anesthesiologists' Classification) I and II status undergoing elective caesarean section, willing to give written informed consent were included.

Exclusion criteria were refusal to participate in the study, opioid use for the past month, history of selective serotonin reuptake inhibitors use, significant pulmonary or cardiovascular disease, cases of eclampsia/ preeclampsia, history of peptic ulcer disease or gastro intestinal bleeding, those with any intraoperative complications and hypersensitivity or any systemic contraindications to the use of study medications. All patients had cesarean section under spinal anaesthesia. The spinal was performed using a 25-gauge Quincke needle with hyperbaric bupivacaine $5 \mathrm{mg} / \mathrm{ml}$. No other intraoperative analgesia was given. The patients were allocated into two groups with 30 cases in each. One group received intramuscular pentazocine $30 \mathrm{mg}$ and another group received pentazocine $30 \mathrm{mg}$ and piroxicam $20 \mathrm{mg}$. The study drug was administered immediately after surgery, intramuscularly on the operating table, after the skin closure by the attending anesthetist. Demographic data, history, clinical and obstetrical examination findings were recorded.

\section{Assessment tools}

\section{Primary outcome measure}

Control of postoperative pain - assessed every 2 hours for a period of 12 hours after surgery by visual analogue scale (VAS) (Figure 1).

\section{Secondary outcomes}

- Sedation: Assessed by Ramsay sedation score (Table 1).
- $\quad$ Time to rescue analgesia: Time for first rescue analgesia (diclofenac $75 \mathrm{mg}$ )

- Safety: Monitoring the adverse drug reactions i.e., maternal and neonatal adverse outcomes.

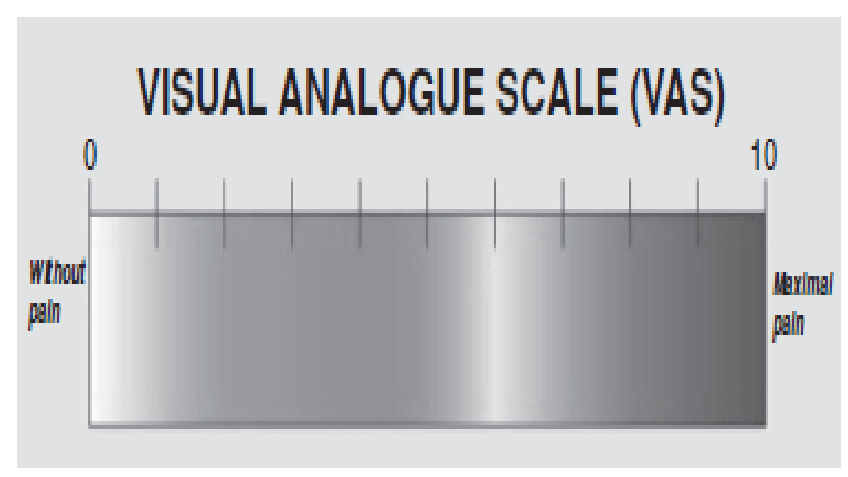

Figure 1: Visual analogue scale used to measure pain.

Table 1: Ramsay sedation score.

\begin{tabular}{|ll|}
\hline Points & Level of activity \\
\hline 1 & Anxious and agitated or restless, or both \\
\hline 2 & Cooperative, oriented, and calm \\
\hline 3 & Responsive to commands only \\
\hline 4 & $\begin{array}{l}\text { Exhibiting brisk response to light glabellar } \\
\text { tap or loud auditory stimulus }\end{array}$ \\
\hline 5 & $\begin{array}{l}\text { Exhibiting a sluggish response to light } \\
\text { glabellar tap or loud auditory stimulus }\end{array}$ \\
\hline 6 & Unresponsive \\
\hline
\end{tabular}

\section{Statistical analysis}

The sample size was 30 in each arm.

Between the two treatment groups the statistical comparison of different parameters was done using student's independent sample t test.

Within each treatment group the data analysis and comparison between mean VAS scores at different points was done by analysis of variance (ANOVA) followed by post hoc test.

\section{RESULTS}

The baseline characteristics like age, weight, mean BP, pulse rate, type of spinal anesthesia used (hyperbaric bupivacaine) were similar in both the unimodal and multimodal study groups (Table 2).

This eliminated the possible confounding influence of these factors.

VAS pain scores over 12 hours duration, reduced in both the treatment groups and the reduction was statistically significant $(\mathrm{p}<0.0001$ by repeated measure ANOVA). 
Table 2: Baseline characteristics.

\begin{tabular}{|llll|}
\hline & Pentazocine & $\begin{array}{l}\text { Pentazocine } \\
\text { +Piroxicam }\end{array}$ & $\begin{array}{l}\text { p } \\
\text { value }\end{array}$ \\
\hline $\begin{array}{l}\text { Age in years } \\
\text { Mean (SD) }\end{array}$ & 25.41(3.94) & 26.41(3.4) & 0.2 \\
\hline $\begin{array}{l}\text { Weight in Kg } \\
\text { Mean (SD) }\end{array}$ & $58(5.75)$ & $60(5.14)$ & 0.15 \\
\hline $\begin{array}{l}\text { Systolic BP } \\
\text { (mm of Hg) }\end{array}$ & $116(3.2)$ & $118(4.9)$ & 0.06 \\
\hline $\begin{array}{l}\text { Diastolic BP } \\
\text { (mm of Hg) }\end{array}$ & $74(2.2)$ & $72.9(4.2)$ & 0.2 \\
\hline $\begin{array}{l}\text { Pulse rate } \\
\text { Mean(SD) }\end{array}$ & $90.12(12.9)$ & $94(15.1)$ & 0.9 \\
\hline $\begin{array}{l}\text { Respiratory rate } \\
\text { Mean(SD) }\end{array}$ & $14.8(1.4)$ & $14.7(1.17)$ & 0.06 \\
\hline
\end{tabular}

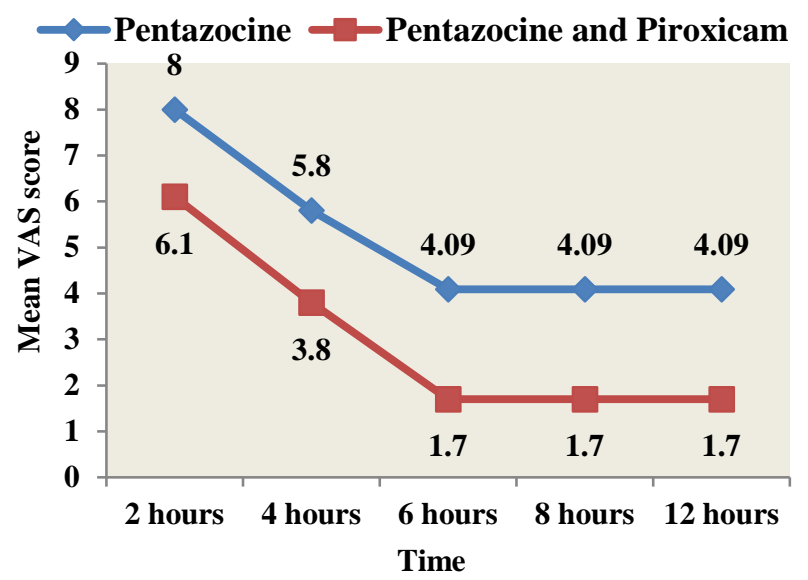

Figure 2: VAS scores in Pentazocine and Pentazocine+Piroxicam.
Table 3: Comparison of Pentazocine versus Pentazocine+piroxicam.

\begin{tabular}{|llll|} 
& Pentazocine & $\begin{array}{c}\text { Pentazocine } \\
\text { +Piroxicam }\end{array}$ & p value \\
\hline $\begin{array}{l}\text { Mean VAS } \\
\text { score }\end{array}$ & $5.2(0.6)$ & $3(0.48)$ & 0.001 \\
Mean (SD) & & & \\
\hline $\begin{array}{l}\text { Time to } \\
\text { first rescue } \\
\text { analgesia } \\
\text { in hours }\end{array}$ & $2.5(0.38)$ & $6(1.72)$ & $<0.05$ \\
Mean (SD) & & & \\
\hline $\begin{array}{l}\text { Mean } \\
\text { sedation } \\
\text { score } \\
\text { Mean (SD) }\end{array}$ & $2.7(0.504)$ & $2.5(0.4302)$ & 0.1037 \\
\hline
\end{tabular}

Mean VAS score with the multimodal group (pentazocine+piroxicam) was 5.2 and that with unimodal group (pentazocine alone) was 3 , VAS scores showed statistically significant difference $(\mathrm{p}<0.001)$. Pentazocine+Piroxicam showed better reduction in pain compared to pentazocine alone (Table 3).

Time to first rescue analgesia in pentazocine group was 2.5 hours and in pentazocine + piroxicam group it was 6 hours (Table 3). Multimodal group (pentazocine +piroxicam) showed a longer time to rescue analgesia compared to unimodal group (pentazocine alone) and the difference was statistically significant $(\mathrm{p}<0.001)$.

Sedation score with pentazocine was 2.7 and that with pentazocine+piroxicam was 2.5 , mean sedation score was comparable in both the groups.

Table 4: Comparison of pain scores over different time points.

\begin{tabular}{|lllllll|} 
& 2 Hours & 4 Hours & 6Hours & 8 Hours & 12 Hours & p value \\
& Mean (SD) & Mean (SD) & Mean(SD) & Mean (SD) & Mean (SD) & ANOVA \\
\hline Pentazocine & $8(0.6)$ & $5.8(0.8)$ & $4.09(0.85)$ & $4.09(0.85)$ & $4.09(0.85)$ & $<0.001$ \\
\hline Pentazocine+Piroxicam & $6.1(1.15)$ & $3.8(0.8)$ & $1.7(0.48)$ & $1.7(0.48)$ & $1.7(0.48)$ & $<0.001$ \\
\hline ' $\mathrm{t}$ ' & 8.1 & 9.44 & 12.6 & 12.6 & 12.6 & \\
\hline $\mathrm{p}$ value ${ }^{\#}$ (t test) & $<0.001$ & $<0.001$ & $<0.001$ & $<0.001$ & $<0.001$ \\
\hline
\end{tabular}

Table 5: Results of post-hoc test (applied to mean VAS scores).

\begin{tabular}{|lllllll|} 
& 2 Hours & 4 Hours & 6 Hours & $\mathbf{8}$ Hours & 12 Hours & p value \\
& Mean (SD) & Mean (SD) & Mean (SD) & Mean (SD) & Mean (SD) & pen \\
\hline Pentazocine & $8(0.60)$ & $5.82 *(0.78)$ & $4.08^{*}(0.85)$ & $4.08^{*}(0.85)$ & $4.08^{*}(0.85)$ & $<0.001$ \\
\hline Pentazocine+Piroxicam & $6.09(1.15)$ & $3.86 *(0.8)$ & $1.68^{*}(0.4)$ & $1.68 *(0.48)$ & $1.68 *(0.48)$ & $<0.001$ \\
\hline
\end{tabular}

*In both the groups there was significant difference when any of the VAS Scores was compared with the corresponding 2hours VAS Score by post-hoc test.

When VAS scores were compared between the two groups at 2 hours, 4 hours, 6 hours, 8 hours and 10 hours, there was significant difference in the pain scores at all time points. 
In pentazocine and pentazocine +piroxicam group when pain scores were compared within the groups, there was significant decrease in pain score over 12 hours duration (by repeated measures ANOVA). In both the groups, when any of the mean VAS scores was compared with the corresponding 2hours VAS score by post-hoc test, significant difference was noted (Table 5).

Table 6: Adverse drug reactions.

\begin{tabular}{|l|l|l|}
\hline $\begin{array}{l}\text { Adverse drug } \\
\text { reaction }\end{array}$ & $\begin{array}{l}\text { Pentazocine } \\
\text { Nausea }\end{array}$ & $\begin{array}{l}\text { Pentazocine } \\
+ \text { piroxicam }\end{array}$ \\
\hline Drowsiness & $6.67 \%$ & $20 \%$ \\
\hline Cough & $10 \%$ & $26.6 \%$ \\
\hline Pain at injection site & $6.67 \%$ & $0 \%$ \\
\hline No ADR & $3.33 \%$ & $0 \%$ \\
\hline
\end{tabular}

The most common adverse drug reaction in the study was drowsiness.

\section{DISCUSSION}

Cesarean section patients have compelling reasons to achieve optimal postoperative pain relief, because they are expected to recover expeditiously and to care for their newborns within a few hours following surgery. Consequently, it is necessary that pain relief is safe and effective, that it does not interfere with the mother's ability to care for her infant, and that it results in no adverse neonatal effects in breast-feeding women. However, although research in this field is increasing, there is no 'gold standard' for post-caesarean pain management. ${ }^{10}$

Postoperative pain is a complex and multifactorial symptom that requires a thoughtful approach using a variety of treatment modalities to obtain an optimal outcome after surgery. Multimodal (or 'balanced') analgesia represents an approach to preventing postoperative pain where the patient is administered a combination of opioid and non-opioid analgesic drugs that act at different sites within the central and peripheral nervous systems in an effort to minimize opioid use and, therefore, to decrease opioid-related side effects. ${ }^{11}$

Today at the dawn of the 21 st century, the best available evidence indicates a major gap between an increasingly sophisticated understanding of the pathophysiology of pain and widespread inadequacy of its treatment. ${ }^{12}$

In this study, after parenteral administration of the drugs mean VAS scores with pentazocine and pentazocine+piroxicam groups were 5.2 and 3 respectively, the average VAS score was lesser in the multimodal group compared to unimodal group and hence, multimodal analgesic combination showed superior analgesic property. Combination of opioid and NSAID might have led to the synergistic action in pain reduction as these two analgesics act by different mechanisms of action and at different sites in nervous systems resulting in additive or synergistic analgesia with lowered adverse effects. Combination of NSAID i.e., piroxicam with pentazocine showed longer time to rescue analgesia compared to the pentazocine given alone. Both the groups showed similar sedation with no statistical difference.

Both the groups showed reduction in pain score over 12 hours; however, combination of pentazocine and piroxicam group showed significant difference in pain reduction at all time points compared to the unimodal group i.e., pentazocine alone.

Pentazocine is a potent analgesic, with both agonist and antagonist action at opioid receptors; it has no antiinflammatory or antipyretic function, it is a weak antagonist at $\mu$ opioid receptors. Its analgesic action is derived from an agonist action on $\mathrm{k}$ receptors, which interrupts pain pathways in the spinal cord. ${ }^{13}$

Combination therapy of analgesics from different groups is advantageous in targeting both peripheral and central pain pathways and hence, helps in production of analgesia at lower and more tolerable doses of the constituent drugs. Combination therapies can have a positive influence on the ability of individual components to minimize pain, with better tolerability and reduced recovery time. ${ }^{14}$

The additive analgesic effects of opioids and NSAIDs are well documented. ${ }^{15}$ Non-steroidal anti-inflammatory drugs (NSAIDs) like paracetamol, diclofenac and oxicams widely used in ambulatory surgery are beneficial in mild to moderate pain and have a well recognized opioid sparing role and effective when administered pre-, peri- and post-operatively. ${ }^{16}$

Similar results were seen in a previous study by Adeniji and Atanda, to compare the effectiveness of intramuscular pentazocine $(60 \mathrm{mg})$ and tramadol (100 $\mathrm{mg}$ ) as single analgesic agents and combinations of tramadol or pentazocine with intramuscular piroxicam 20 $\mathrm{mg}$, for the management of post-cesarean section pain. The author concluded that the multimodal approach was better than the unimodal approach, tramadol had a faster onset of action, but pentazocine had a longer duration of action and provided better control of pain. The author also concluded, among the multimodal groups, the combination of pentazocine with piroxicam was superior to the tramadol with piroxicam combination. ${ }^{17}$

This finding is also consistent with the report of the study by Kuti et al, in which pentazocine was compared with tramadol for pain relief in the intrapartum period. This study showed that both pentazocine and tramadol were safe for the relief of labour pain. Pentazocine however provided better pain relief than tramadol in labor, but it was associated with higher incidence of drowsiness. These findings were similar to our study because the 
most common adverse effect seen with pentazocine was drowsiness. In pentazocine group incidence of drowsiness was $10 \%$ and it was $26.6 \%$ with pentazocine+ piroxicam group.

It is also possible that the better pain control seen with pentazocine might be related to its sedative effects on the postoperative anxieties often exhibited in many patientsas sedative effect could diminish the anxiety associated with the outcome and processes of labor. ${ }^{18,19}$

However, it is noteworthy that most reports in the literature have not extended the comparison of the efficacy of these two agents beyond the first 6-hour postoperative period. In our study, the VAS scores were recorded every 2 hours upto 12 hours after giving the drug and, comparison of VAS scores between different study groups was done at all time points i.e., 2,4,6,8 and 12 hours.

A randomised controlled trial done by Adamou et al, to compare pentazocine versus combined pentazocine and diclofenac for pain relief in the first 48 hours after caesarean section showed that the use of combined analgesia (pentazocine and diclofenac) compared to single-agent analgesia was safe, significantly reduced pain and improved patient satisfaction during postoperative period following caesarean section. ${ }^{20}$

The sedative effect of pentazocine was maintained across all groups and was greater in the pentazocine+piroxicam group with no untoward adverse reaction. No adverse reaction was recorded in any breastfed neonates, which is similar to the findings of another study. ${ }^{17}$

Both the drugs were safe and there were no serious adverse drug events with any of the drugs. Drowsiness was the main adverse drug reaction.

The limitation of this study is the possible confounding influence of the spinal analgesia agent (bupivacaine) on the observed analgesic effects of all agents studied; however, we reason that since all the patients had the same drug and dosage for the spinal analgesia, except for individual patient peculiarity, this effect should balance out. Long term adverse effects with the drugs could not be assessed as adverse drug reactions were recorded only for 12 hours after giving the single dose of the study drug. Opioid analgesic sparing action of NSAID could not be assessed as the doses of tramadol and pentazocine were same both in unimodal groups and in combination groups.

\section{CONCLUSION}

In conclusion, in a resource-poor setting like India, where more potent opioids are not readily available and affordable, this study has shown that a multimodal approach of combining pentazocine with a NSAID, such as piroxicam, would achieve better pain relief and maternal satisfaction following cesarean section.

Funding: No funding sources

Conflict of interest: None declared

Ethical approval: The study was approved by the Institutional Ethics Committee

\section{REFERENCES}

1. Buvanendran A, Kroin JS, Tuman KJ. Effects of perioperative administration of a selective cyclooxygenase 2 inhibitor of pain management and recovery of function after knee replacement. JAMA. 2003;290:2411-8.

2. White PF, Sacan O, Tufanogullari. Effect of short term postoperative celecoxib administration on patient outcome after outpatient laparoscopic surgery. Can J Anaesth. 2007;54:342-8.

3. Ashburn MA, Caplan RA, Carr DB. Practice guidelines for acute pain management in the perioperative setting. An updated report by the American Society of Anesthesiologists task force on acute pain management. Anesthesiology. 2004; 100:1573-81.

4. WHO. Int [homepage on the Internet]. WHO's cancer pain ladder for adults. World Health Organization; 2012 [cited July 28, 2013]. Available from: http://www.who.int/cancer/palliative/painladder/en/. Accessed June 27, 2014

5. Henderson K. Pentazocine. Update in Anesthesia 2008; 24(1) Available from: www.worldanaesthesia.org:8-12. Accessed July 22, 2014.

6. Olofsson CI, Legeby MH, Nygards EB, Ostman KM. Diclofenac in the treatment of pain after caesarean delivery. An opioid-saving strategy. Eur J Obstet Gynecol Reprod Biol. 2000;88(2):143-6.

7. Wilder-Smith CH, Hill L, Dyer RA, Torr G, Coetzee E. Postoperative sensitization and pain after Cesarean delivery and the effects of single IM doses of tramadol and diclofenac alone and in combination. Anesth Analg. 2003;97:526-33.

8. RobertsII LJ, Morrow JD. Analgesicc-antipyretic and antiinflammatory agents and drugs employed in the treatment of gout. In: Hardman JG, Limbard LE, Goodman gilman A. The pharmacological basis of therapeutics. 10 ${ }^{\text {th }}$ Ed. New York: Mc Grow Hill; 2001:713-714.

9. Mitra S, Khandelwal P, Sehgal A. Diclofenactramadol vs diclofenac-acetaminophen combinations for pain relief after caesarean section. Acta Anaesthesiol Scand. 2012;56(6).

10. Verstraete S, Van de Velde M. Post-cesarean section analgesia. Acta Anaesthesiol Belg. 2012;63(4):14767.

11. Multimodal analgesia: its role in preventing postoperative pain. [cited 2017 Mar 6]. Available from: 
http://www.medscape.com/medline/abstract/1818353 4

12. Pain Management: A Fundamental Human Right: Anesthesia \& Analgesia [Internet]. LWW. [cited 2017 Mar 6]. Available from: http://journals.lww.com/anesthesiaanalgesia/Fulltext/2007/07000/Pain_Management_ A_Fundamental_Human_Right.37.aspx

13. Karen Henderson. Pentazocine. Update in Anaesthesia. Available from: http://www.worldanaesthesia.org. http://update.anaesthesiologists.org/wpcontent/uploads/2009/10/Pentazocine.pdf. Accessed February 12, 2013.

14. Raffa RB. Pharmacology of oral combination analgesics: rational therapy for pain. J Clin Pharm Ther. 2001;26(4):257-64.

15. McQuay HJ, Carroll D, Watts PG, Juniper RP, Moore RA. Codeine $20 \mathrm{mg}$ increases pain relief from ibuprofen $400 \mathrm{mg}$ after third molar surgery. A repeatdosing comparison of ibuprofen and an ibuprofencodeine combination. Pain. 1989;37(1):7-13.

16. Sinatra RS. Acute pain management and acute pain services. In: Cousins MJ, Bridenbaugh PO, editors. Neural Blockade in Clinical Anesthesia and
Management of Pain. $2^{\text {nd }}$ Ed. Philidelphia: Lippincott-Raven; 1998:793-835.

17. Adeniji AO, Oluseyi OA. Randomized comparison of effectiveness of unimodal analgesia with multimodal analgesia in post-cesarean section pain management. Journal of pain research. 2013;6:419-24.

18. Kuti O, Faponle AF, Adeyemi AB, Owolabi AT. Pain relief in labour: A randomized controlled trial comparing pentazocine with Tramadol. NJOG. 2008;3(1):14-8.

19. Bricker L, Lavender T. Parenteral opioids for labor pain relief: a systematic review. Am J Obstet Gynecol. 2002;186(5): S94-109.

20. Adamou N, Tukur J, Muhammad Z, Galadanci H. A randomised controlled trial of opioid only versus combined opioid and non-steroidal anti inflammatory analgesics for pain relief in the first 48 hours after Caesarean section . Niger Med J. 2014;55:369-73.

Cite this article as: Banapura A, Mamatha KR, Prabha P. Pentazocine versus pentazocine with piroxicam for postoperative pain relief after cesarean section: an open label, comparative study. Int J Basic Clin Pharmacol 2017;6:1393-8. 